\author{
تأثير لايه زئوتكستايل در كاهش آبشستخى موضعى بايه استوانهاى بِل \\ على نورى امامزادهيى ‘* منوجهر حيدريورّ، محمدرضا نورى امامزادهيى و بهزاد قربانى

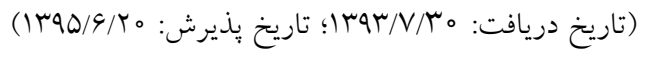

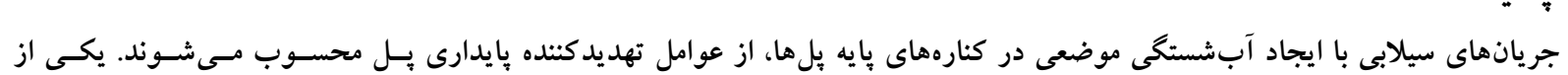

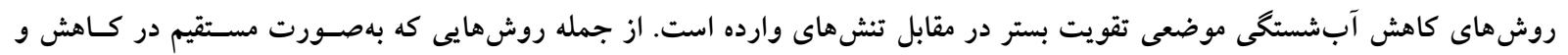

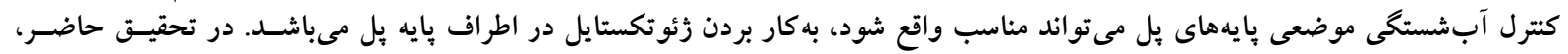

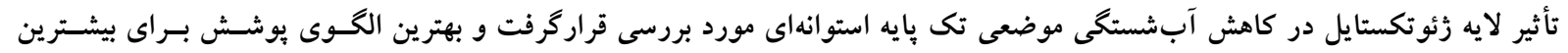

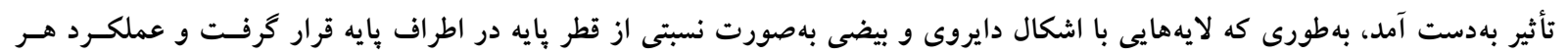

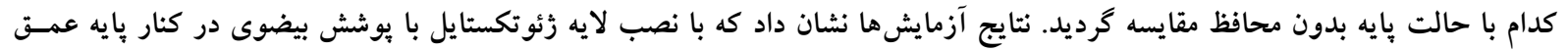

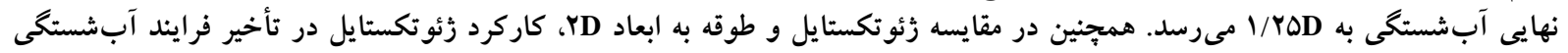

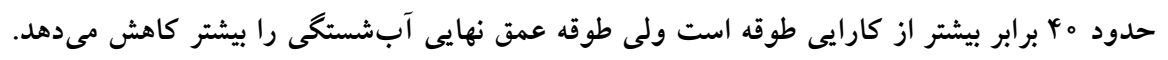

وازههاى كليدى: آب شستخى موضعى، گرداب برخاستخى، پايه پِل، زُئوتكستايل، قطر بايه

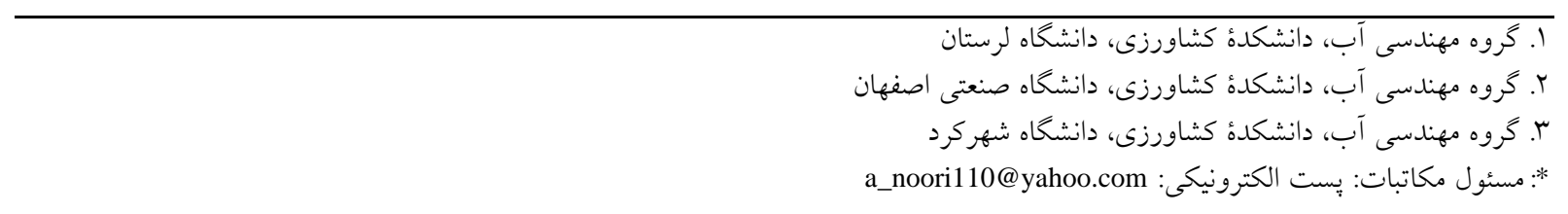


توزيع زمانى آبشتشكى در كنـار بايـه محافظـت شـده توسط

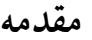

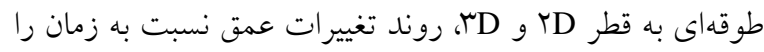

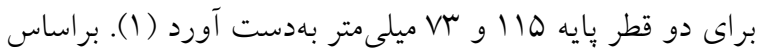

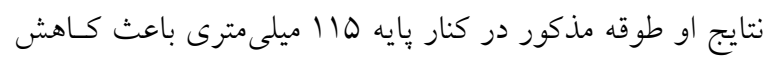

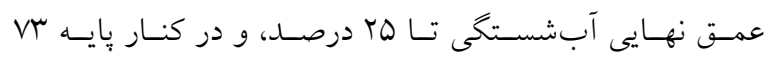

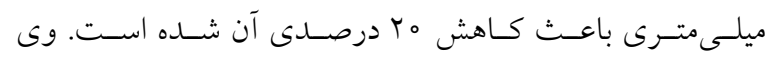

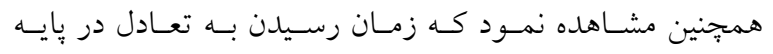

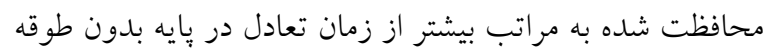
است. زئوتكستايلها كه از الياف يلى يروييلن و يلى اسـتر توليــــ

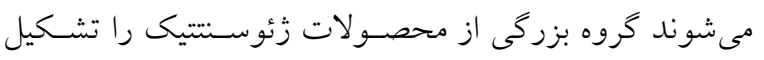
داده و و از نظر سـاختار تجـارى در دو دسـته بافتـه شـــه و

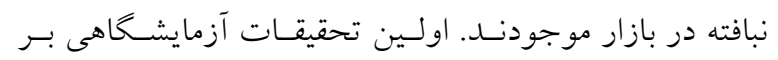

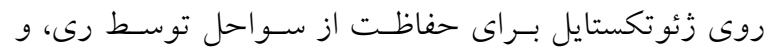

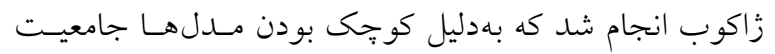

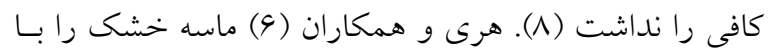

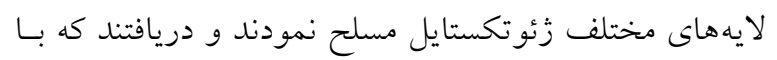

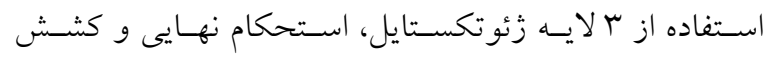

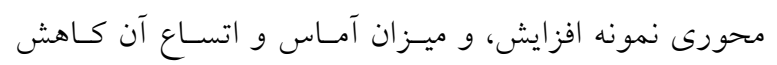

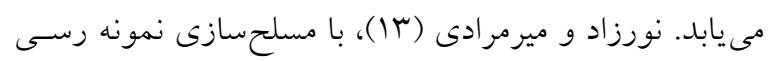

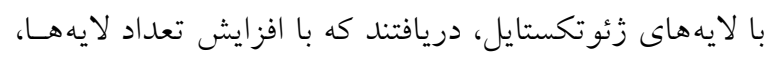

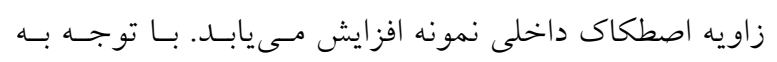

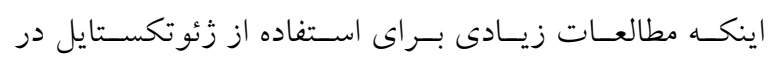

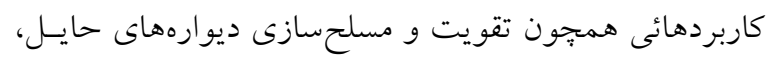

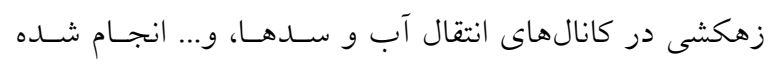

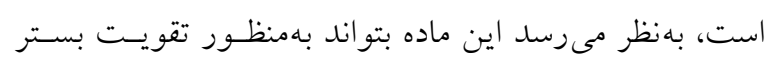

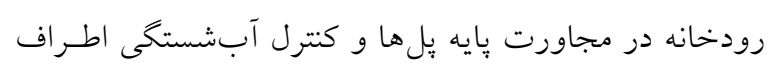

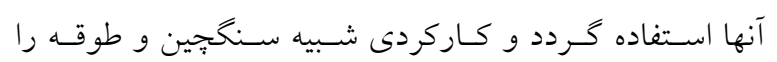

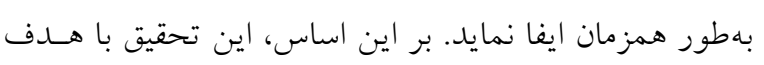

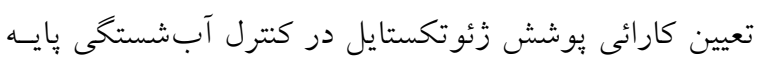

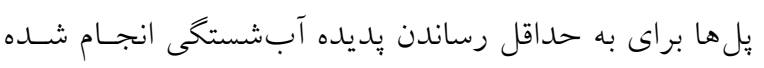

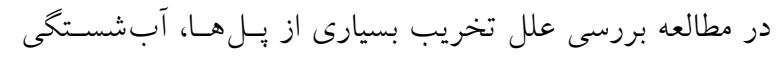

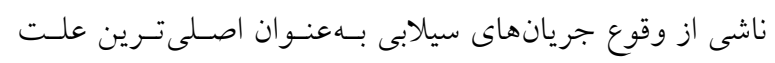

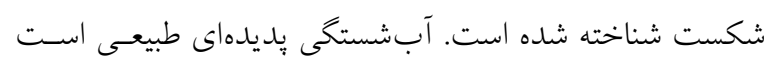

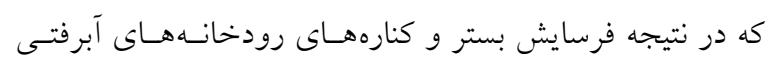

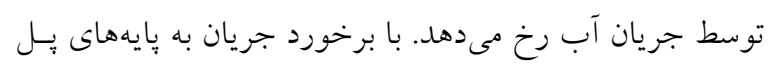

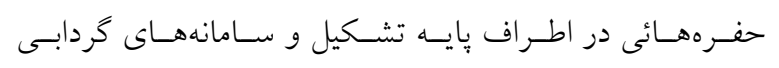

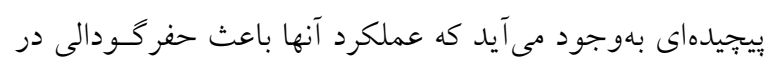

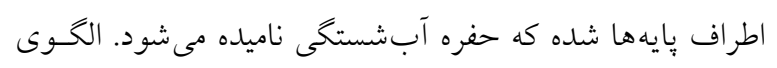

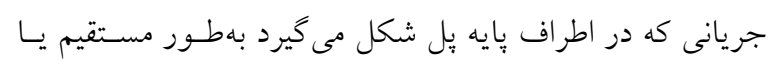

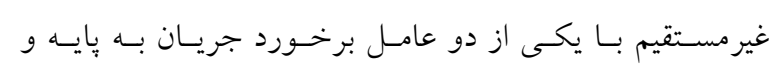

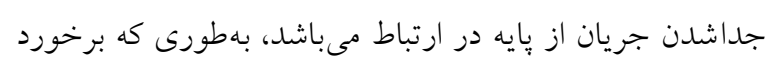

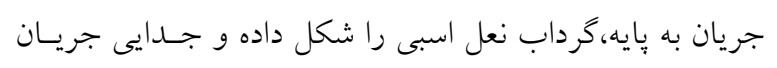

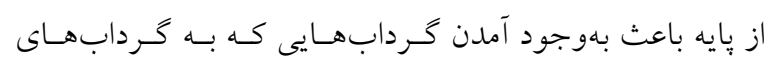

$$
\text { برخاستخى موسومند، مىشود. }
$$

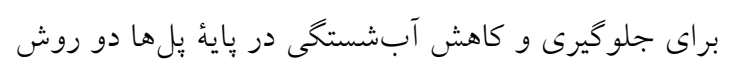

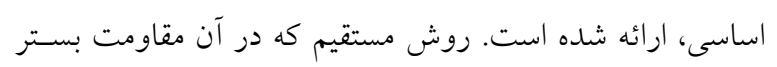

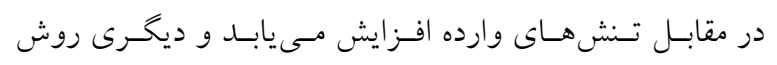

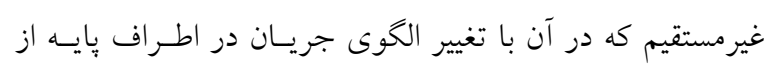

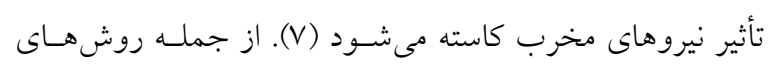

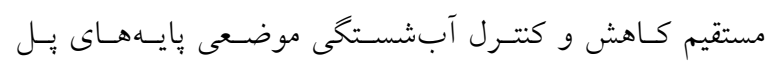

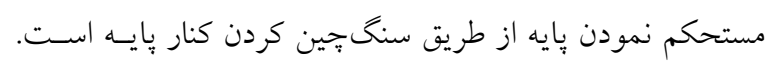

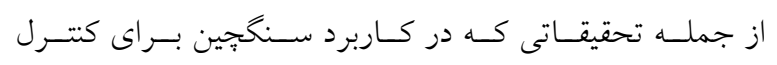

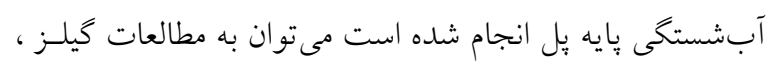

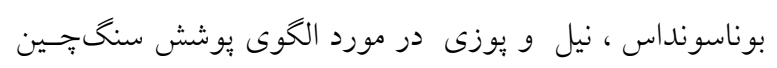

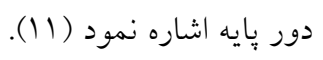
از روشهاى غيرمستقيم در كاهش آبشستخى نيز مى دـوان

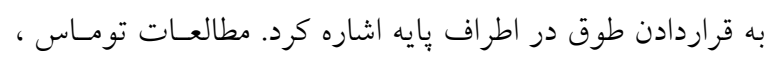

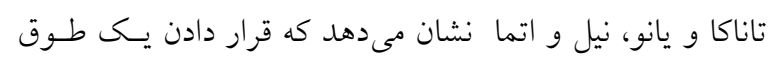

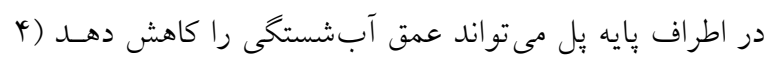

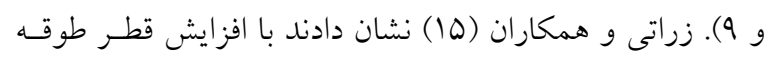

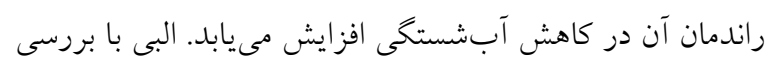



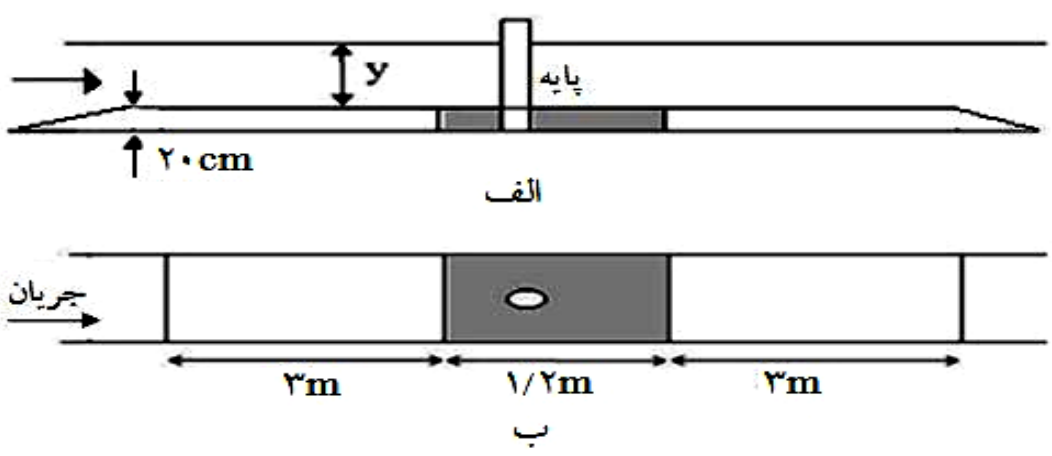

شكل (. الف) يروفيل طولى و ب) يِلان محل نصب سكوها و منطقه مورد آزمايش

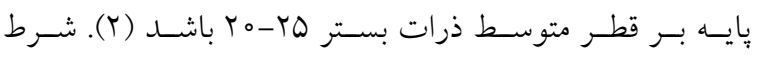

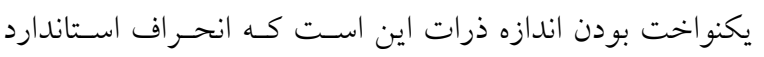

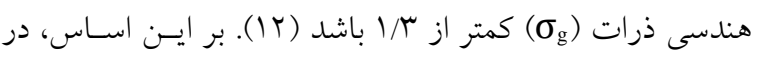

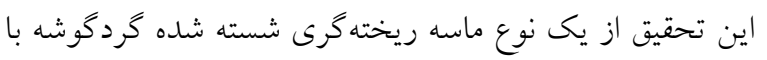

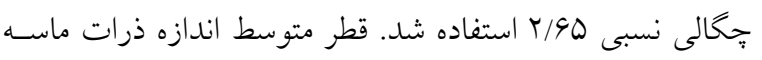

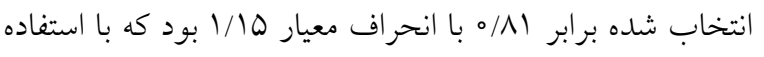

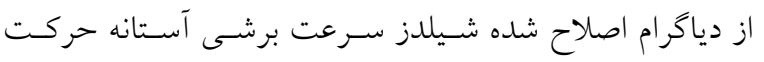

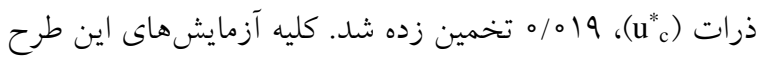
با شيب طولى كانال معادل صفر درجه و با دبى هolit/Sec انجام شد. براساس نظر رودكيوى مبنى بر اين كه نسبت عرض كانسال

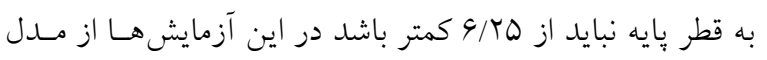

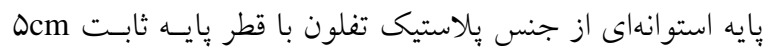

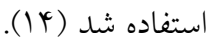
به منظور تعيين شرايط هيدروليكى جريان، قبل از نصب پايه

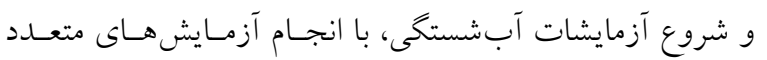

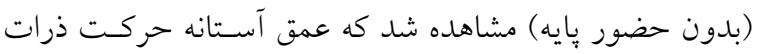

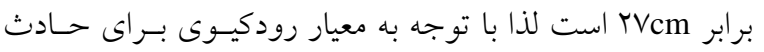

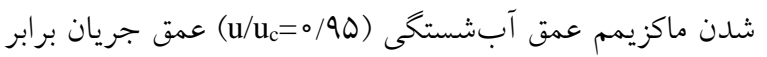

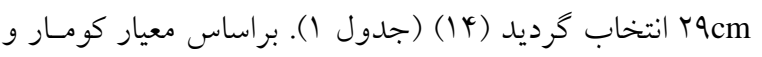

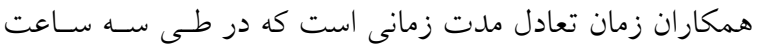

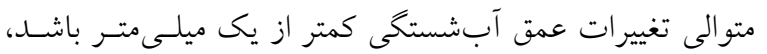

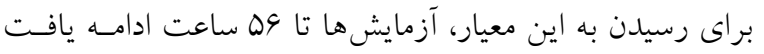

\section{مواد و روشها}

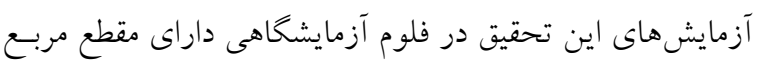

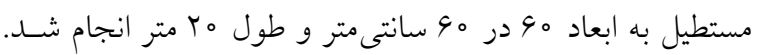

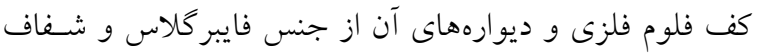

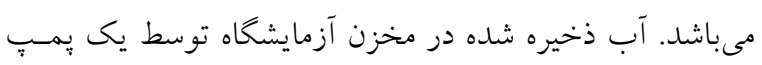

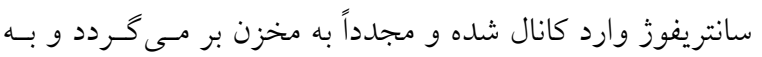

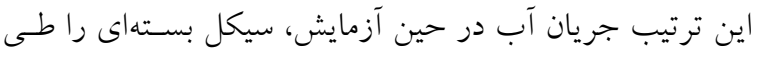

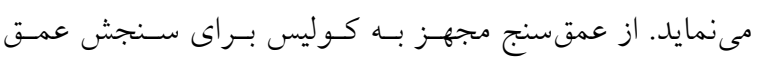

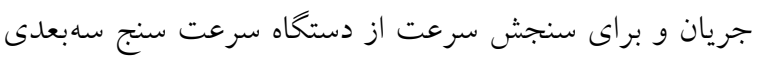

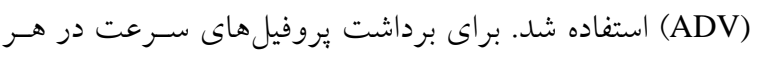

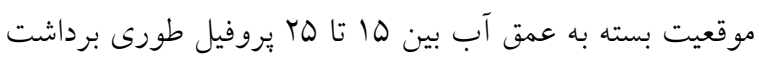

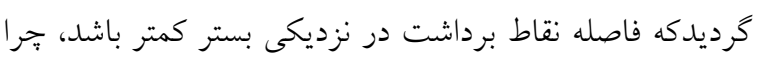

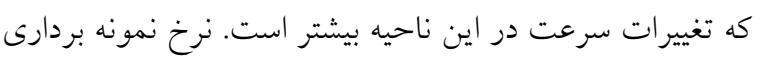

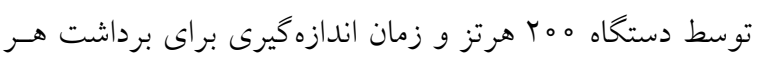

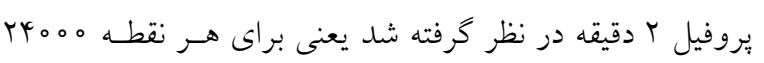

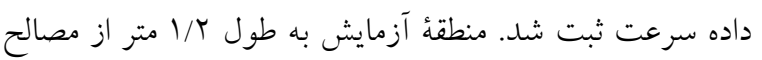

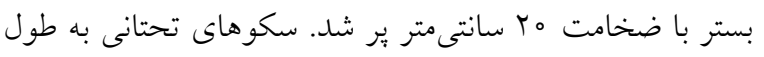

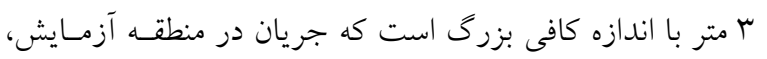
توسعه يافته محسوب گردد (شكل (1).

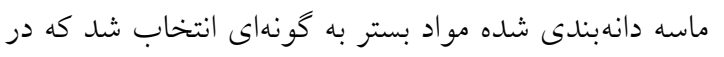

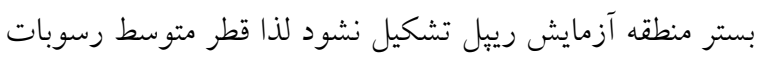

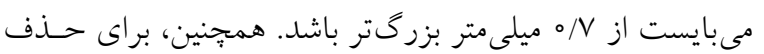

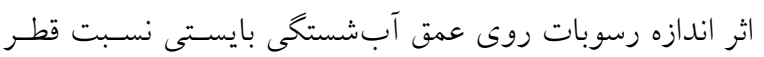


جدول ا. شرايط هيدروليكى جريان در آزمايش

\begin{tabular}{|c|c|c|c|c|c|c|c|c|}
\hline $\mathrm{Fr}$ & $\mathrm{u} / \mathrm{u}_{\mathrm{c}}$ & $\mathrm{u}^{*}{ }_{\mathrm{c}}(\mathrm{m} / \mathrm{s})$ & $\mathrm{u}_{\mathrm{c}}(\mathrm{m} / \mathrm{s})$ & $\mathrm{y} / \mathrm{d}$ & $y(m)$ & $\mathrm{d} / \mathrm{D}_{\diamond}$ 。 & $\mathrm{D}_{\iota_{\circ}}(\mathrm{mm})$ & $\mathrm{d}(\mathrm{mm})$ \\
\hline$\circ / \backslash \wedge \vee$ & $0 / 94$ &.$/ 0190$ & O/MY. & $\Delta / \Lambda$ & $0 / \pi q$ & $41 / V$ & $\circ / \Lambda \mid$ & $\Delta_{0}$ \\
\hline
\end{tabular}

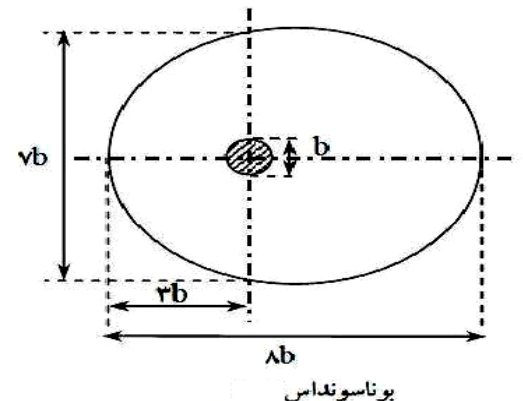

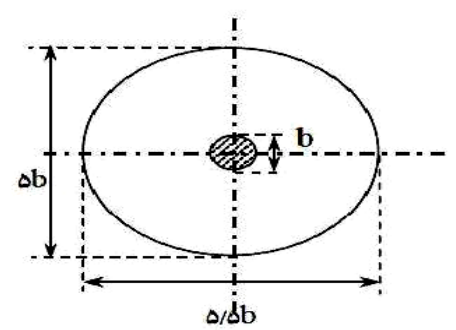

كيلز

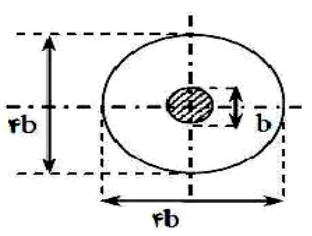

نيل

شكل r. الكوهاى اوليه براى اندازه بوشش زئوتكستايل

\begin{tabular}{|c|c|c|c|}
\hline كميت & روش آزمايش & واحد & مشخصه \\
\hline roo & DIN EN $Y ৭ \circ V r / l$ & $\mathrm{~g} / \mathrm{m}$ & جرم در واحد سطح \\
\hline r & DIN EN $r q \circ V r / r$ & $\mathrm{~mm}$ & ضخامت \\
\hline rq & DIN EN $r q \circ V r / r$ & $\mathrm{KN}$ & حداكثر كشش طولى و عرضى \\
\hline $4 / 1$ & DIN EN ISOITrMG & $\mathrm{KN} / \mathrm{m}$ & مقاومت سوراخ (CBR) \\
\hline$r / 4$ & DIN EN ISO $1 \cdot \circ \Delta$ & $\mathrm{m} / \mathrm{sec} 10^{-r}$ & نقوذيذيرى آب در جهت عمودى \\
\hline $1 \mu^{\prime} \circ$ & ASTM D rarr & $\mathrm{N}$ & نيروى قابل انبساط و كشش طولى و عرضى \\
\hline 010 & ASTM D ratr & $\mathrm{N}$ & استحكام يارگى ذوزنقه در طول و عرض \\
\hline$v r_{0}$ & ASTM D & $\mathrm{N}$ & شاخص فشردن و مقاومت \\
\hline
\end{tabular}

به آرامى در فلوم برقرار شد. مشاهده گَرديد كه با ايجاد گـرداب

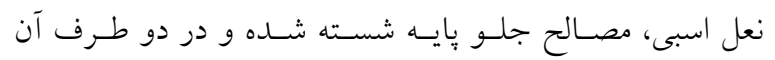

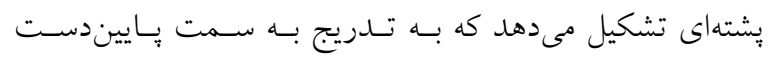

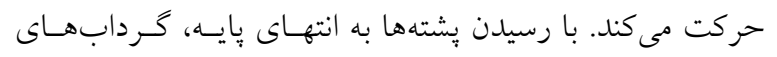

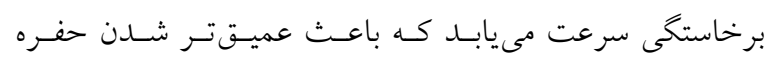

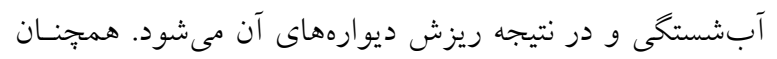

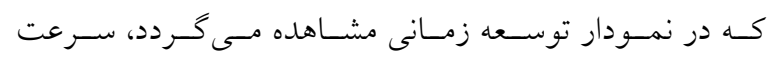

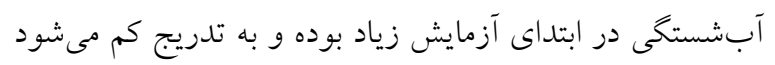

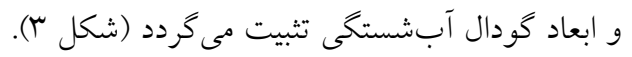

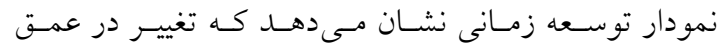

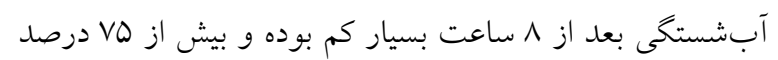

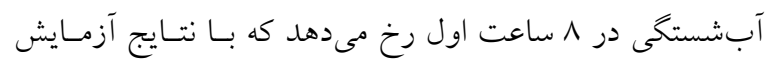

هندسه صفحات زئوتكستايل در آزمايشهاى اين تحقيق شـامل

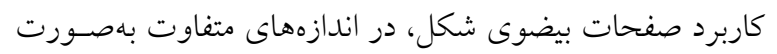

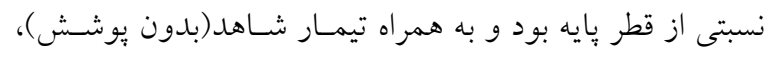

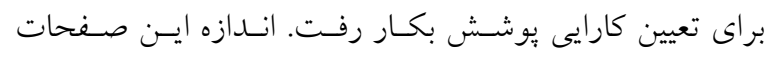

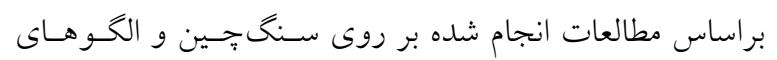

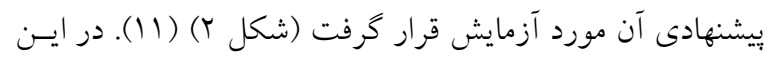

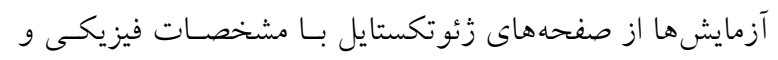
مكانيكى مذكور استفاده شد (جدول ب r).

\section{نتايج و بحث}

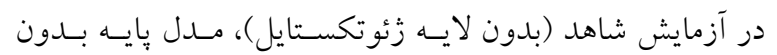

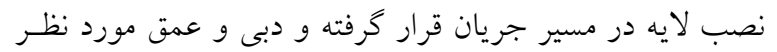


تأثير لايه زئوتكستايل در كاهش آبشستخى موضعى بايه استوانهاى بل
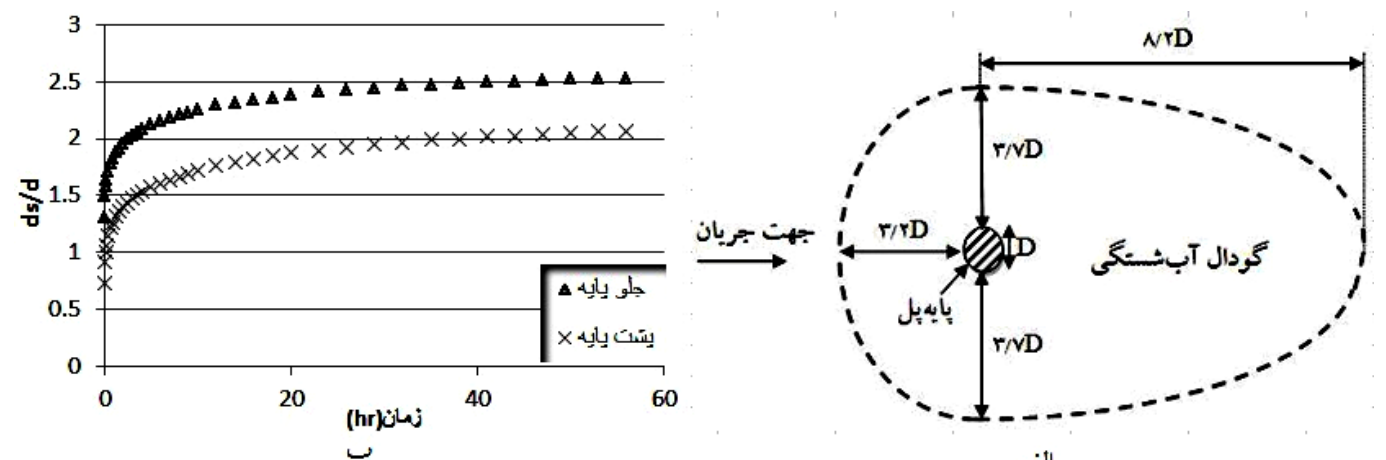

شكل r. الف) ابعاد گودال نهايى تشكيل شده و ب) توسعه زمانى آبشستخى، بدون لايه زئوتكستايل
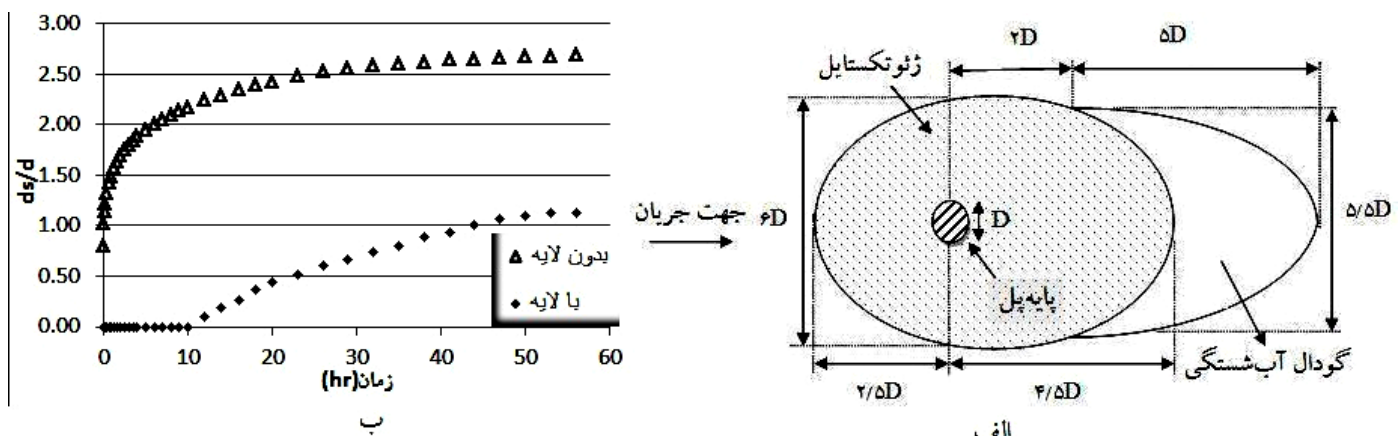

شكل f. الف) ابعاد لايه و كودال حفر شده و ب) توسعه زمانى آبشستخى در الكوى بيشنهادى بوناسونداس در ناحيه گودال

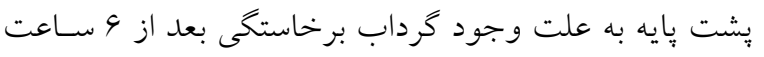

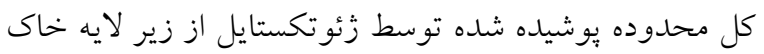

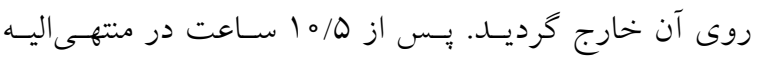

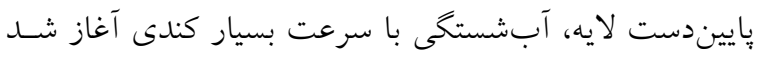
كه به سمت پايييندست داراى توسعه طولى، عرضى و عمقىى

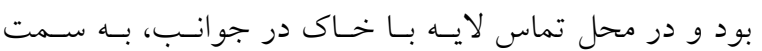

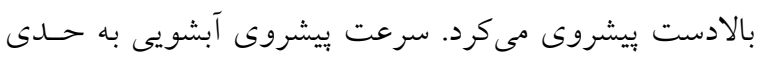

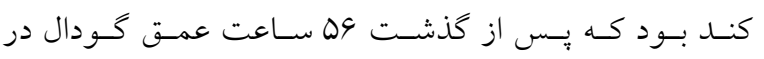

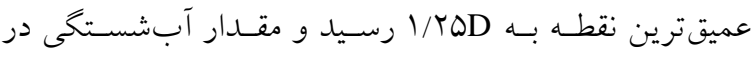

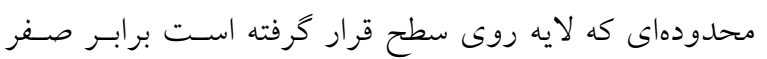

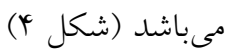

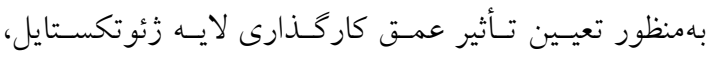

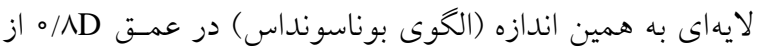

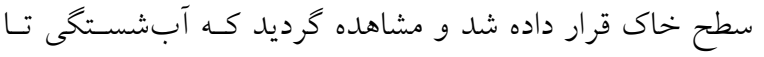

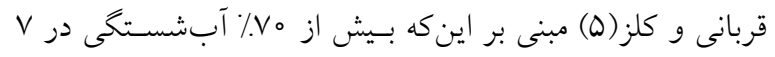

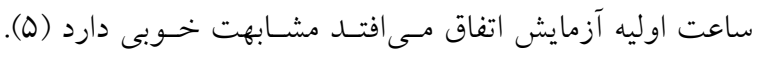

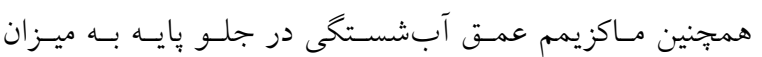

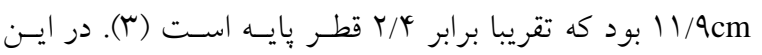

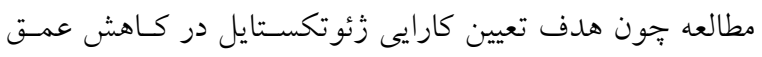

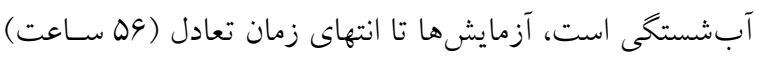

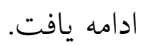
به بعنوان تيمار اول لايه زئوتكستايلى به اندازه ارائسه شـده

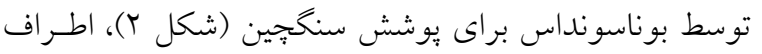

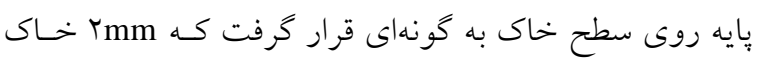

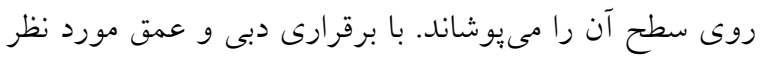
مشاهده شد كه به علت گرداب نعل اسبى در همان دقيقه اول

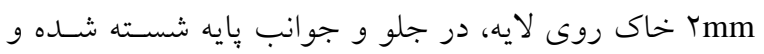
سطح زئوتكستايل مشخص گرديد. اين در حالى است كـه در 


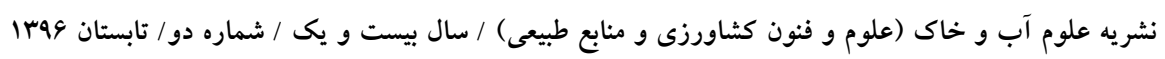
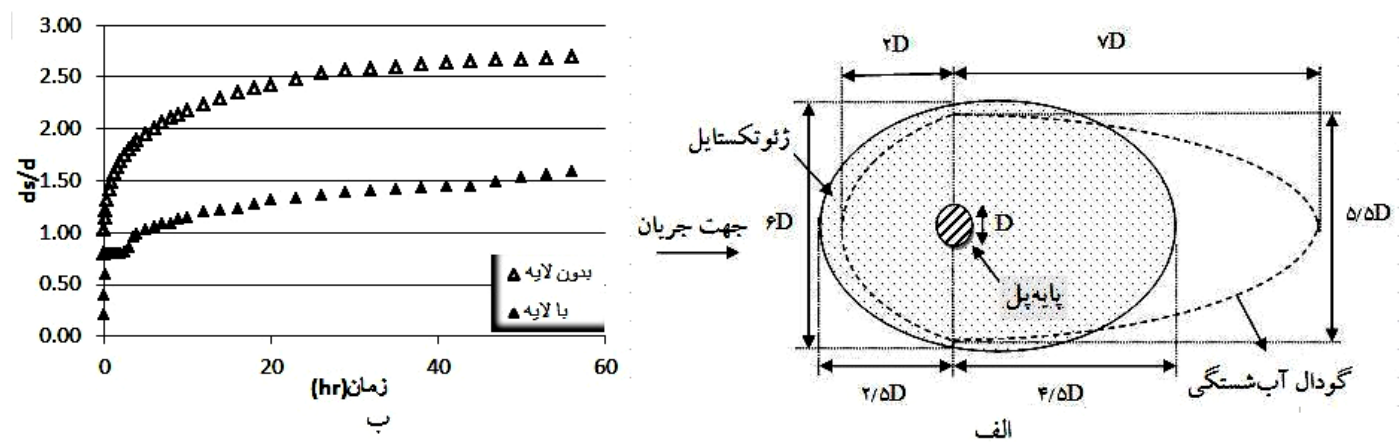

شكل ه. الف) ابعاد گودال حفر شده و ب) توسعه زمانى آبشستخى در الكوى ييشنهادى بوناسونداس در ناحيه گودال
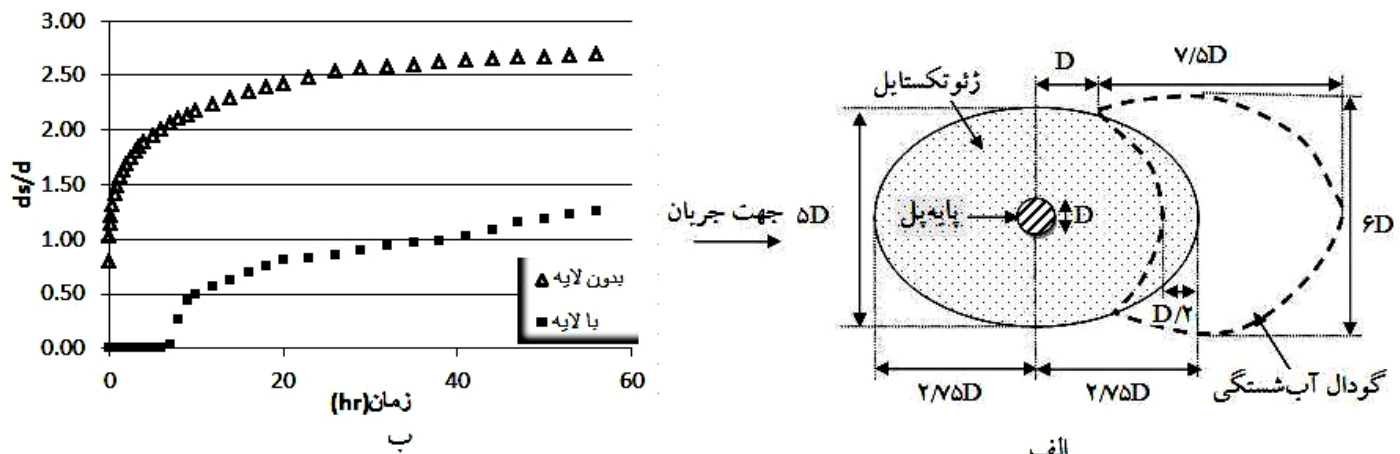

شكل و. الف) ابعاد لايه و كودال حفر شده و ب) توسعه زمانى آبشستخى در الكوى بيشنهادى گيلز در ناحيه گودال

كـه از همــه لحساظ از حالـت يوشـش بيضـوى (بوناسـونداس)

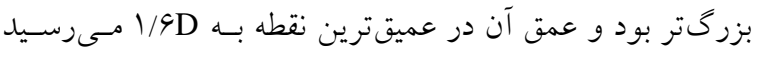

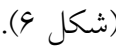

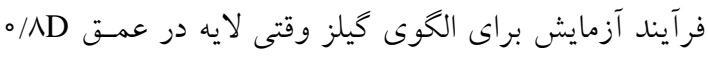

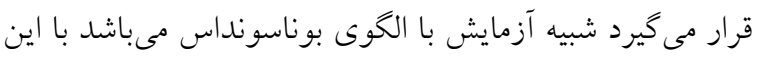

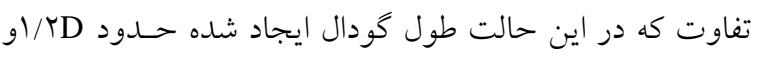
عرض آن حدود AD/ه افزايش نشان مى داد.

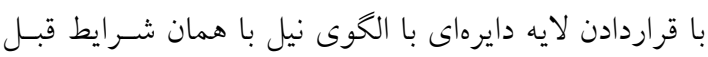

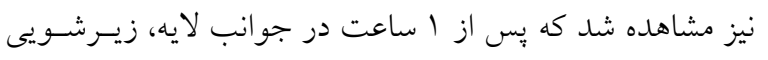

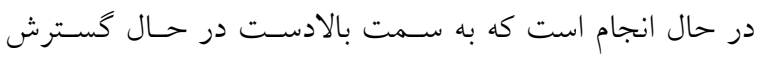

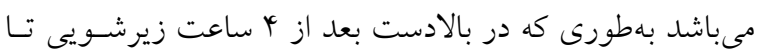

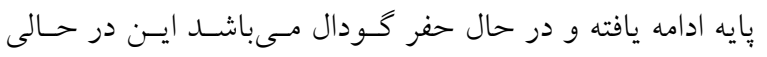

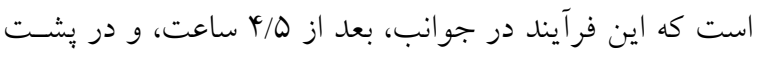

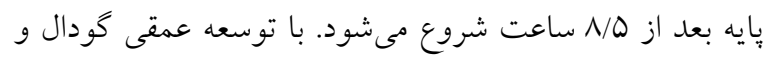

سطح لايه مانند حالتى كه لايه وجود ندارد ادامه يافته و پس از از

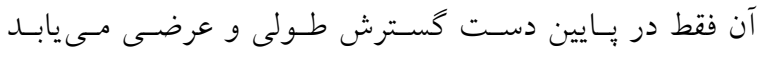

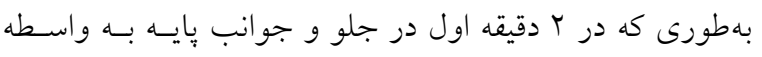

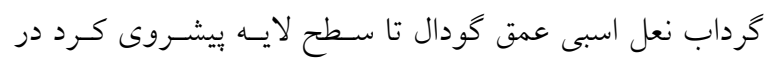

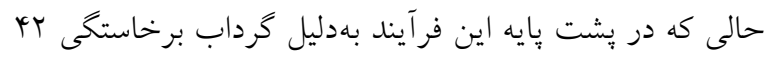
دقيقه به طول انجاميد (شكل هالم).

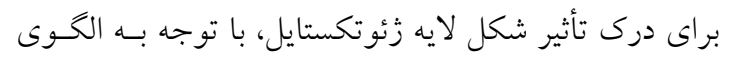

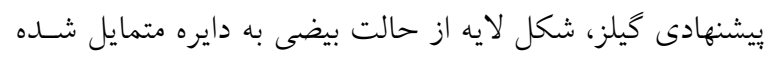

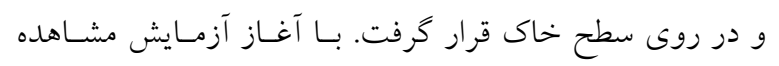

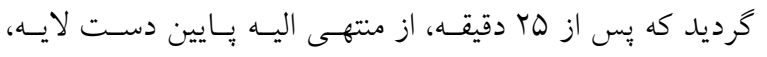

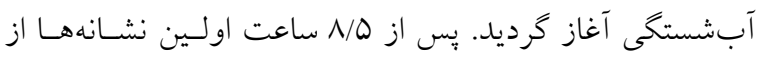

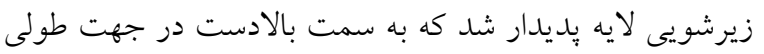

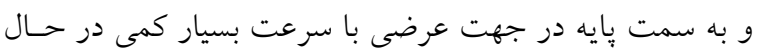

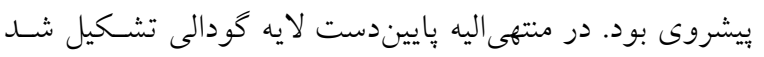




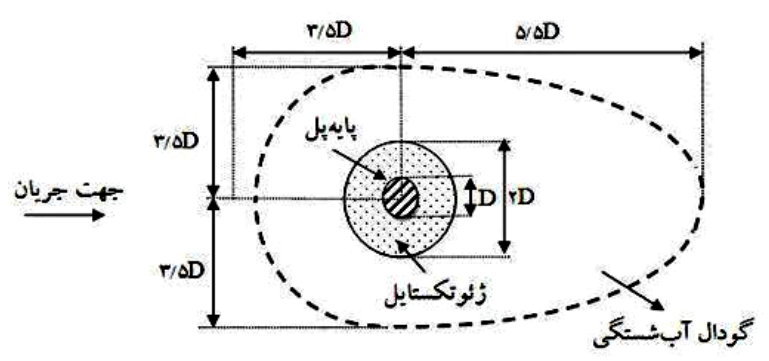

الف

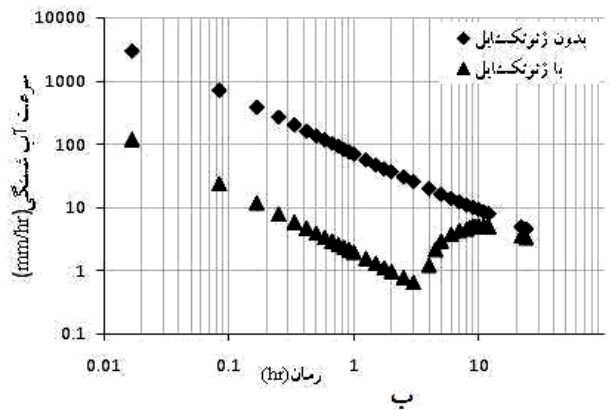

ب

شكل V. الف) ابعاد كودال حفر شده و ب) منحنى مقايسهاى سرعت آبشستخى در كاربرد لايه با الكوى نيل

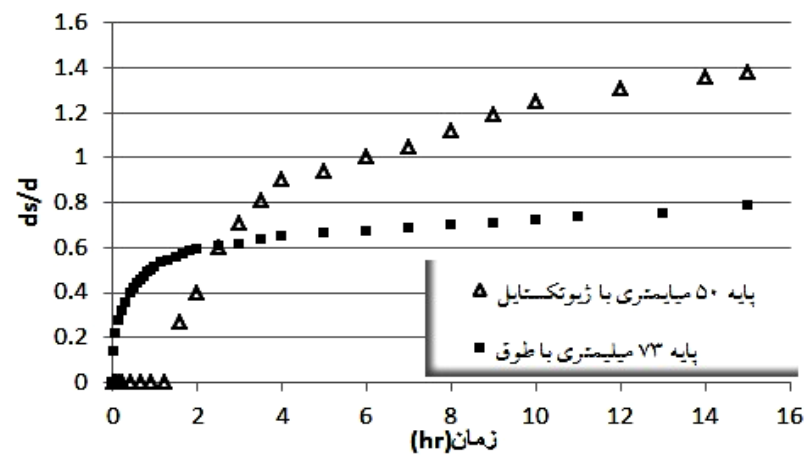

شكل 1 مقايسه نتايج آزمايشهاى آلبى (1) بر روى طوقه، با نتايج آزمايش زئوتكستايل به ابعاد بماد

عمق آبشستخى با سرعت بيشترى نسبت به آزمايش مشابه بـا

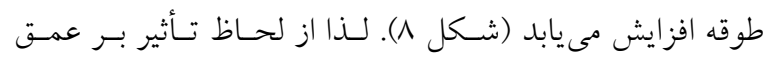

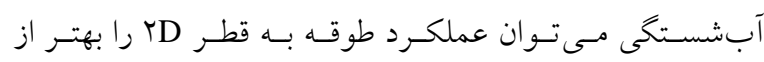

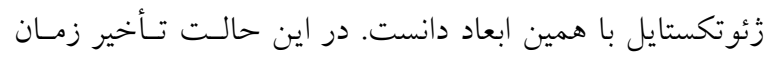

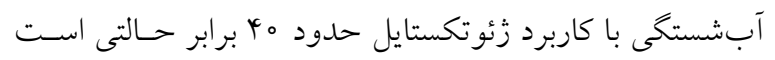
كه از طوقه استفاده مى كردد.

$$
\text { نتيجه گيرى }
$$

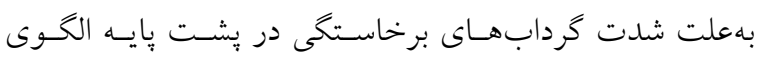

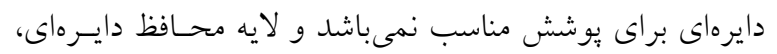

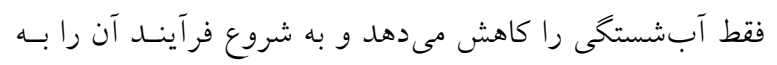
تأخير مى اندازد.

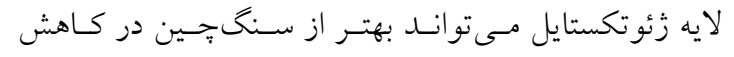

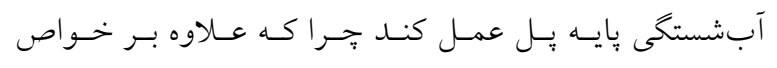

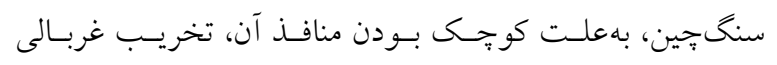

خالى شدن زيرلايه زئوتكستايل، لبههاى لايه بهدليل انعطاف

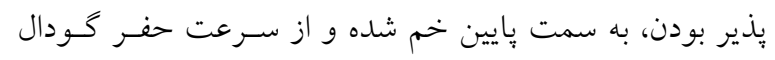

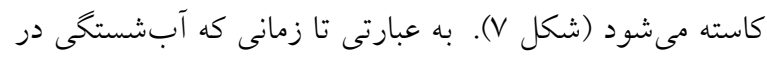

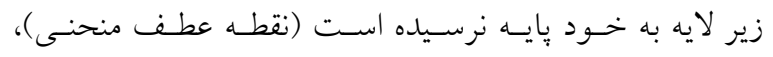

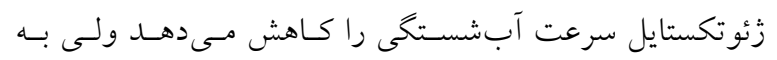

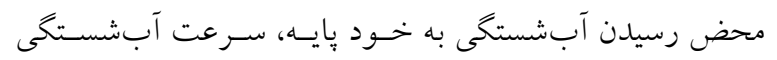

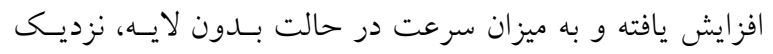
مى شود (شكل V V اب).

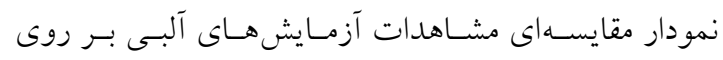

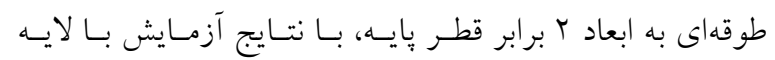

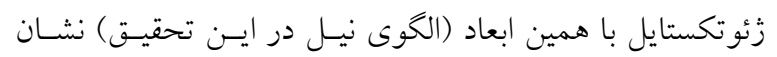

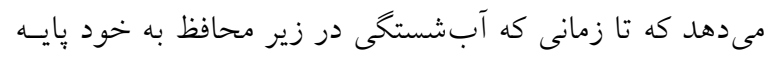

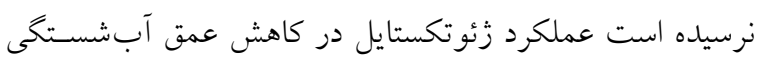

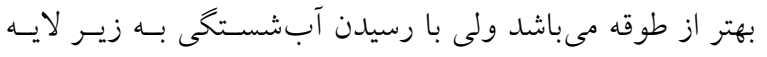
بهدليل خمشدن لبههاى زئوتكستايل در اثـر نيــروى وزن سـيال 


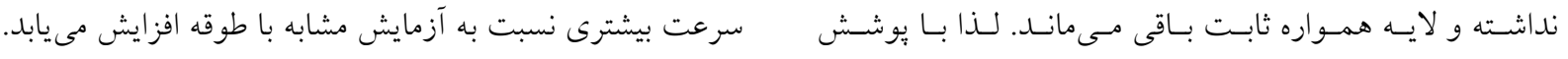

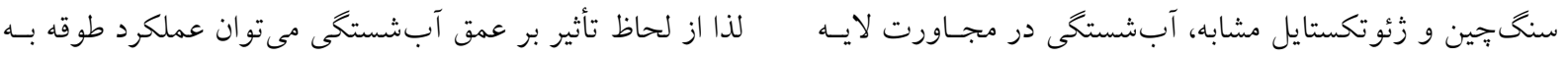

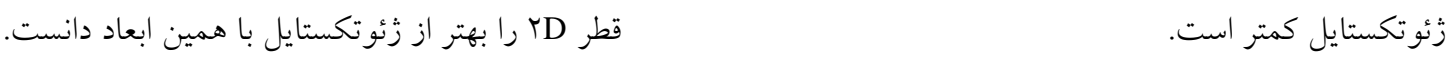

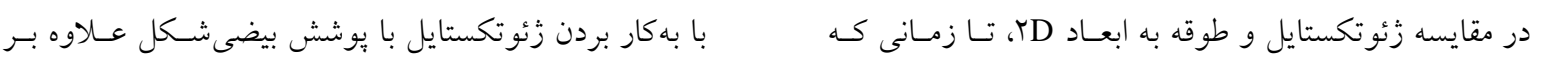

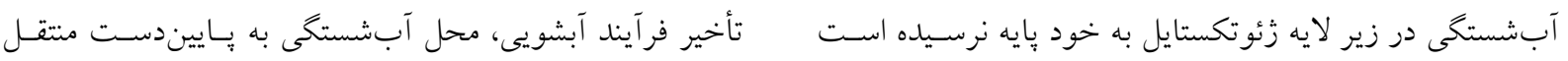

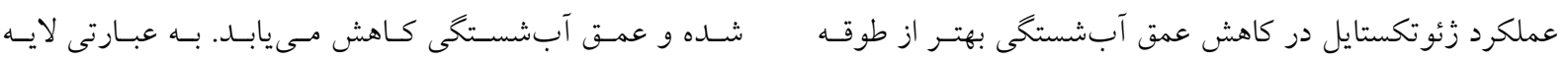

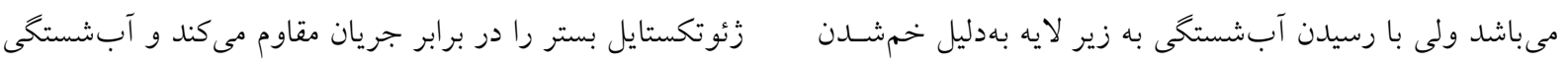

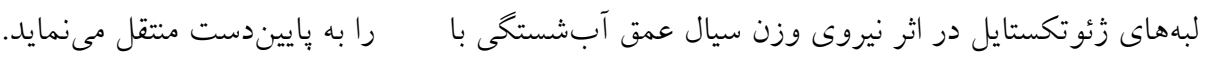

\section{منابع مورد استفاده}

1. Alabi, P. D. 2006. Time development of local scour at bridge pier fitted with a collar. Master degree thesis, Faculty of Civil Engineering, Universityof Saskatchewan, Canada.

2. Breusers, N. H. C., G. Nicollet and H. W. Shen. 1977. Local scour around cylindrical piers. J. Hydraulic Research, IAHR. 15(3): 211-252.

3. Chiew, Y. M. 2004. Local scour and riprap stability at bridge piers in a degrading channel. J. Hydraulic Engineering, ASCE. 130(3): 218-226.

4. Ettema, R. 1980. Scour at bridge piers. Dept. of Civil Engineering, University of Auckland, New Zealand, Report No. 112.

5. Ghorbani, B. and J. A. Kells. 2008. Effect of submerged vanes on the scour occurring at a cylindrical pier. J. Hydraulic Research, IAHR. 46(5): 610-619.

6. Hari, S. M., R. Noorzad and A. M. Oskoorouchi. Effect of geotextile reinforcement on the mechanical behavior of sand. J. Geotextiles and Geomembranes 18(6): 385-402

7. Heidarpour, M., Z. Khodarahmi and S. F. Mousavi. 2003. Control and reduction of local scour at bridge pier groups using slot. 30th IAHR Congress, 301-307. Thessaloniki, Greece.

8. Hornsey, W. P., J. T. Carley and R. J. Coghlan 2011. Geotextile sand container shoreline protection systems: Design and application. J. Geotextiles and Geomembranes 29(4): 425-439.

9. Izadinia, E. and M. Heidarpour. 2012. Simultaneous use of cable and collar to prevent local scouring around bridge pier. J. Sediment Research 27(3): 394-401.

10. Kummar, V., K. G. RangaRaju and N. Vittal. 1999. Reduction of local scour around bridge piers using slot and collar. J. Hydraulic Engineering ASCE. 125(12): 1302-1305.

11. Mashahir, M. B., A. R. Zarrati and E. Mokallaf. 2010. Application of riprap and collar to prevent scouring around rectangular bridge piers. J. Hydraulic Engineering, ASCE. 136(3): 183-187.

12. Melville, B. W. and Y. M. Chiew. 1999. Time scale for local scour at bridge piers. J. Hydraulic Engineering, ASCE. 125(1): 59-65.

13. Noorzad, R. and S. H. Mirmoradi. 2010. Laboratory evaluation of the behavior of a geotextile reinforced clay. J. Geotextiles and Geomembranes 28(4): 386-392.

14. Raudkivi, A. J. 1998. Loose boundary hydraulics. A. A. Balkema. $4^{\text {th }}$ Edition. 2-512. Rotterdam, The Netherland.

15. Zarrati, A. R., M. Nazariha and M. B. Mashahir. 2006. Reduction of local scour in the vicinity of bridge pier groups using collars and riprap. J. Hydraulic Engineering, ASCE. 132(2): 154-162. 


\title{
The Effect of Geotextile Layer in Decreasing Local Scour of Cylindrical Bridge Pier
}

\author{
A. Nouri Emamzadehie ${ }^{1^{*}}$, M. Heidarpour ${ }^{2}$, M. R. Nouri Emamzadehei ${ }^{3}$ \\ and B. Ghorbani ${ }^{3}$
}

(Received: Oct. 22-2014; Accepted: Sept. 10-2016)

\begin{abstract}
Flood currents are considered threatening factors by creating local scour along bridge piers. One method for decreasing local scour is to strengthen the bed against imposed tensions. Among methods which can directly be appropriate in decreasing and controlling local scour of bridge piers is to employ geotextile around bridge piers. In the present study, the effect of geotextile layer in decreasing local scour of cylindrical single-pier was investigated with the purpose of proposing the best effective method of covering bridge pier. So, layers with circular and oval shapes were put around the pier, in proportion with pier diameter, and the performance of each was compared with the unprotected pier. Test results showed that with installing the oval geotextile layer, final scour depth around the pier reached to 1.25D. Also, comparing geotextile and collar with 2D diameter, the delay of scour process around geotextile was 40 times higher than the collar, but the collar decreased the ultimate scour depth further than geotextile.
\end{abstract}

Keywords: Local scour, Wake vortex, Bridge pier, Geotextile, Pier diameter.

1. Dept of Water Eng. College of Agric., Lorestan Univ., Khorramabad, Iran.

2. Dept of Water Eng. College of Agric., Isf. Univ. of Technol., Isfahan, Iran.

3. Dept of Water Eng.-College of Agric., Shahrekord Univ., Shahrekord, Iran.

*: Corresponding Author, Email: a_noori110@yahoo.com 